\title{
Total Recovery of Sinker Weights from Lead-Core Fishing Nets
}

\author{
Masafumi Tateda1, Hiroshi Yamada ${ }^{2}$, Youngchul Kim³ \\ ${ }^{1}$ Department of Environmental Engineering, Toyama Prefectural University, Imizu, Japan \\ ${ }^{2}$ Sato Tekko Co., Ltd., Tateyama, Japan \\ ${ }^{3}$ Department of Environmental Engineering, Hanseo University, Seosan-si, Korea \\ Email: tateda@pu-toyama.ac.jp
}

Received 23 January 2014; revised 21 February 2014; accepted 11 March 2014

Copyright (C) 2014 by authors and Scientific Research Publishing Inc.

This work is licensed under the Creative Commons Attribution International License (CC BY). http://creativecommons.org/licenses/by/4.0/

(c) (i) Open Access

\begin{abstract}
The adverse effects of lead poisoning have long been of environmental concern. A large number of research papers have reported many routes of lead poisoning, of which lead sinkers used in fishing require urgent attention. Lead sinkers that are abandoned or scattered from individual fishing gear are notorious for environmental pollution and have been reported in many papers; moreover, lead-core "sinker rope" is used in fishery nets. This paper discusses the latter, which generally has limited public awareness. Preliminary work and field studies were conducted to develop a system for total treatment of lead from fishing nets with lead-cored sinker ropes, in order to prevent environmental pollution and conserve natural resources. Lead sinkers in fishing nets were successfully removed, yielding high-quality lead suitable for commercial purposes. Appropriate management of fishing nets is crucial for environmental protection and resource conservation.
\end{abstract}

\section{Keywords}

Fishing Net; Lead Sinker; Removal; Recovery; Health Effect

\section{Introduction}

Lead poisoning is of global environmental concern, and has been the subject of extensive research and numerous published reports. Even since 2010, nearly 1 million reports related to lead have been published within Elsevier alone [1]. Meyer et al. (2008) summarized general lead sources as: gasoline, smelters, battery recycling, paint, traditional remedies, and electronics, and specific toys were listed as sources of lead exposure among children [2]. Adverse human health effects include erythrocyte protoporphyrinat blood lead concentration of $20 \mu \mathrm{g} / 100 \mathrm{ml}$ (increased function), peripheral nerve conduction velocity at $40 \mu \mathrm{g} / 100 \mathrm{ml}$ (decreased function), and encephalo- 
pathy at around $150 \mu \mathrm{g} / 100 \mathrm{ml}$, which is the level of death in case of children [2]. In addition, many researchers have reported concerns regarding environmental and human poisoning caused by lead sinkers used in fishing [3]-[22]. Lead sinkers abandoned in the environment have been a main cause of poisoning via ingestion by animals and even children. Some countries such as Denmark and the United Kingdom (England and Wales) have therefore banned the use of lead sinkers in inland waters, and Canada has also banned their use in some areas such as national parks [20]. According to Scheuhammer (2003), the annual loss of lead sinkers and jigs reached approximately 500 tons, representing 14\% of abandoned non-recoverable lead in Canada [12].

Similar estimates are not available for Japan. Lead consumption in Japan was approximately 25,000 tons in 2012, of which 75\% was used for storage battery cells and 3.3\% for lead sinkers and other use, but further details are unknown [23]. The use of lead sinkers evokes secondary environmental concerns, as stated earlier. In Japan, there are two forms of environmental concerns relating to lead sinkers, but there are no published reports on these issues, namely: lead sinkers abandoned and scattered by individual anglers; and lead-core sinker-ropes used for commercial fishing nets. The former case is serious but details are unknown in Japan, therefore an investigation is badly needed; the present paper focuses on the latter case because the authors believe there is a need for greater public awareness. Lead-free fishing sinker has been studied for commercial development but the substitution of lead by other materials such as tungsten-based alloys or cast iron is not easy or realistic in terms of production cost and usability [24].

There is no procedure for the treatment and management of lead-core fishing nets, which represents a negative aspect of the Japanese fishery sector. Deep-sea fishing nets such as fixed location nets and dragnets usually contain lead sinkers in their ropes. There are unofficial claims that those nets are discarded inappropriately, in the backyards of fishers' storage houses and at ports, or released into the oceans [25]. In practice, it is not known how these fishing nets are managed. The secondary environmental impacts associated with the lead sinkers contained in abandoned fishing nets are therefore of great concern. Lead is soluble in water and therefore has the potential to contaminate soil, groundwater, and surface water. As lead sinkers form the core of the rope, they are unlikely to be scattered into environments such as water bodies or to be ingested by animals; however, other exposure pathways have been reported. A nine-year-old cow was reported with neuropilvacuolation, which was attributed to lead poisoning via the fishing nets used to restrain the animal [15]. Many fishing nets were destroyed by the tsunami that followed the Tohoku Great Earthquake of March 2011 in Japan. Many local governments in Japan accepted disaster debris for disposal under the central government guidance. Kanazawa city, located in Ishikawa Prefecture, almost in the center of Japan and adjacent to the Sea of Japan, landfilled approximately 80,000 tons of fishing gear and nets from tsunami-hit areas [26]. Disposal via landfill is currently a main management strategy for fishing nets in Japan [25]. It is unknown what proportion of the disposed 80,000 tons was lead-core rope, but assuming $10 \%$ by weight would represent 8000 tons of lead [25]. Lead abandonment into the environment and even disposal at certified locations is not only a cause of environmental pollution but also represents the abandonment of natural resources [27]-[31]. Lead is also a highly recyclable resource as a base metal.

Preliminary research and a case study were conducted on the collection and removal of lead sinkers from lead-core fishing nets. This paper aims to raise awareness of the need for appropriate management of fishing nets, and to accelerate the removal and collection of lead from fishing nets in order to protect the environment and natural resources.

\section{Materials and Methods}

\subsection{Sample Fishing Nets Containing Lead Sinkers}

Samples were obtained of two types of fishing net: unused nets (Nitto Seimo Co., Ltd.), and used nets from the Tohoku Region that were discarded following the tsunami of March 2011 (Kesennuma Block, Miyagi Prefecture).

\subsection{Analysis of Net Structure and Remaining Lead}

Analysis of net structure; i.e., the quantity of lead, how the sinkers were installed in ropes, and how much remained in ropes after treatment were performed. Manual and visual observations were conducted at the laboratory of either Toyama Prefectural University or Sato Tekko Co., Ltd. 


\subsection{Analysis of Lead Sinker Composition}

The composition of lead sinker in lead-core ropes was analyzed via energy dispersive X-ray spectrometry (EDX —900HS, Shimadzu).

\subsection{Field Experiment of Lead Sinker Recovery}

A field experiment on the removal of lead sinker was performed at Kesennuma Earthquake Disaster Debris Treatment Site (Kesennuma Block) in Miyagi Prefecture, Japan. The experiment used a batch operation-type cross-flow shredder (CFS S-1250, Sato Tekko) consisting of a treatment box containing a chain revolving at $3000 \mathrm{rpm}$. Five kilograms of previously roughly cut lead-core rope from fishing nets was placed into the machine and treatment time was selected as 30,60 , and 90 seconds. Treated ropes and removed lead sinkers were withdrawn from the bottom of the box and stored in a small metal container and a flexible container respectively.

\section{Results and Discussion}

\subsection{Analysis of Lead Sinkers and Net Structure}

Analysis of the lead-core ropes revealed that they were netted to form fishing nets. Therefore, the inclusion of lead sinkers in fishing nets is usually not noticed by the public from the net's outer appearance. Two types of mounted lead sinkers were identified, shown in Figure 1.

The type shown on the right in Figure 1 is string-attached: lead sinkers weights are pinched onto a string in a line and mounted in the core position of the ropes. The type shown on the left in Figure 1 is the tube type: lead weights are packed within a tube and mounted in the core position of the ropes. The black spots in the tube indicate the locations of the lead weights. No spots were visible if there were no lead weights inserted in the tube. Those mounted types of lead sinkers were netted into the ropes; the condition of mounted lead sinkers in the ropes is shown in Figure 2. A rope usually comprised three thinner ropes, each of which included mounted lead sinkers in its core. Table 1 shows the results of laboratory analysis and the weight percentage of lead sinkers in

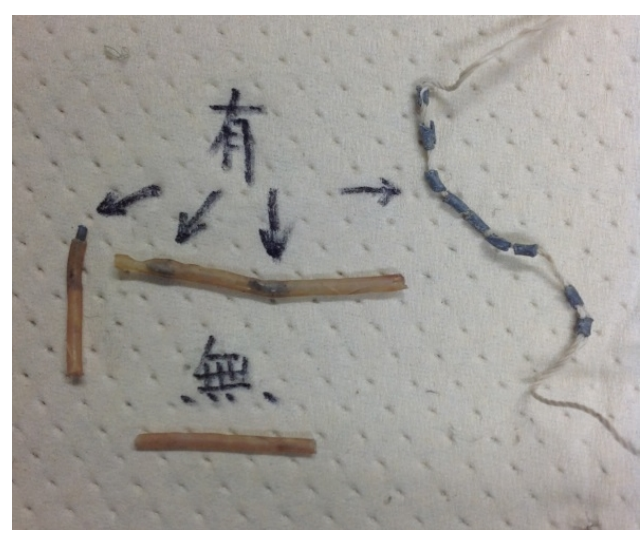

Figure 1. Two mounted types of lead sinkers.

Table 1. Percentage weight of lead sinkers in four kinds of fishing ropes.

\begin{tabular}{cc} 
Rope samples & Weight (\%) \\
\hline A & 42.4 \\
B & 58.4 \\
C & 50.4 \\
D & 34.9 \\
\hline
\end{tabular}


Table 2. Composition of lead sinkers.

\begin{tabular}{cccc}
\hline Element (\%) & Analysis 1 & Analysis 2 & Analysis 3 \\
\hline $\mathrm{Pb}$ & 95.401 & 98.78 & 93.96 \\
$\mathrm{Fe}$ & 3.542 & 1.22 & 1.61 \\
$\mathrm{Sb}$ & 0.417 & - & - \\
$\mathrm{Mn}$ & 0.382 & - & - \\
$\mathrm{Zn}$ & 0.147 & - & 0.06 \\
$\mathrm{Cr}$ & 0.111 & - & 0.26 \\
$\mathrm{Ra}$ & - & - & 4.11 \\
\hline
\end{tabular}

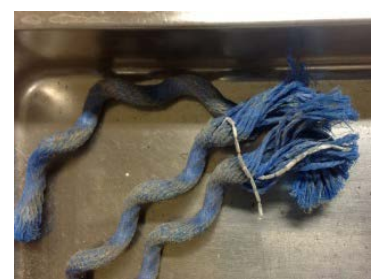

(a)

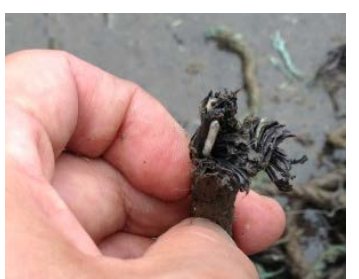

(b)

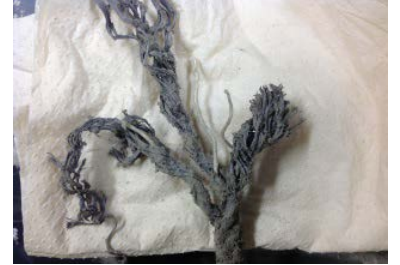

(c)

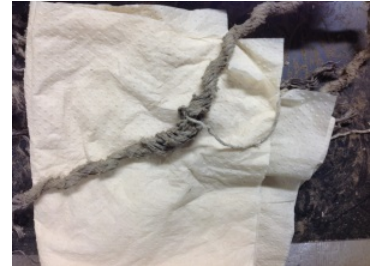

(d)

Figure 2. Condition of mounted lead sinkers in the ropes.

the four types of ropes that were examined.

As seen in Table 1, the fishing nets contained approximately 35\% - 60\% lead sinkers by weight, meaning that 100 tons of fishing net would yield 35 - 60 tons of lead sinkers. The composition of the lead sinkers was analyzed, and the results are shown in Table 2.

The results show that lead sinkers used in fishing nets contain high-purity lead that could be resold as a base metal at a price of at least 1 USD per kilogram. Although the quantity of used fishing net treated for disposal is unknown, it is said that large amounts of used fishing net have been landfilled, especially among disaster debris. The current disposal method for used fishing net implies abandonment of a valuable resource and raises secondary environmental concerns associated with lead toxicity.

\subsection{Field Experiment for Lead Sinker Recovery}

Used fishing net was pre-cut and placed into the shredder for removal of lead sinkers. Figure 3 shows the results of ten experiments at a treatment time of 30 seconds.

Removed lead sinkers weighed about $1.5 \mathrm{~kg}$ and treated used ropes were around $3 \mathrm{~kg}$. The total weight of about $4.5 \mathrm{~kg}$ was less than that placed into the shredder. The weight differential might be attributing to the weight of dirt attached to the rope surface. It was recognized that much dirt attaches to fishing nets during use, and that many kinds of fishing net that initially have a distinctive color become the same color due to dirt ingress. Consequently, it was very difficult to quickly visually distinguish the types of fishing net at the field site. The results show that lead sinker comprised $33.5 \% \pm 0.6 \%$ weight (wet) when water content was $4.5 \%-14.3 \%$. The disparity in these results from the those shown in Table 1 on lead sinker weight percentage is explained by the differing field and laboratory methodologies: in the laboratory, each separated rope type (Table 1) was selected and analyzed for percentage lead content by weight; conversely, the field experiments used unidentified, non-separated, and mixed rope types (Figure 1); as a consequence, the results differed. Removed lead sinker and treated ropes were withdrawn from the bottom of the shredder (Figure 4). The lower container shown in accumulated removed lead sinker and the upper container collected treated ropes. The closed appearance of the removed lead sinker is shown in Figure 5.

\subsection{Differing States of Unused and Used Ropes after Treatment}

Following treatment, the used had an appearance similar to cotton (Figure 6), whereas the unused ropes still the 


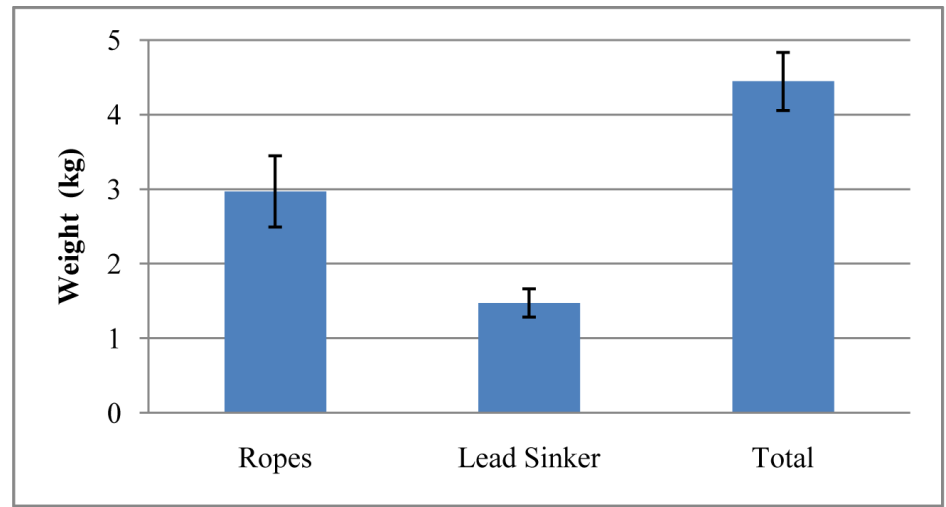

Figure 3. Ropes and lead sinker recovery after treatment by cross-flow shredder.

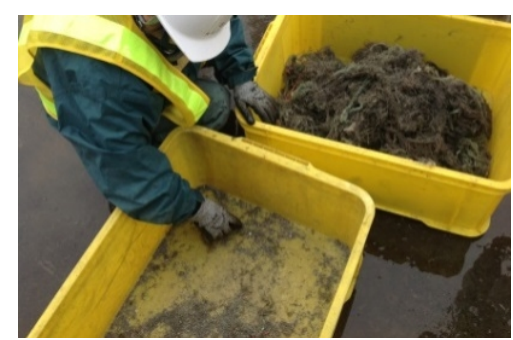

Figure 4. Separation of lead sinkers and ropes.

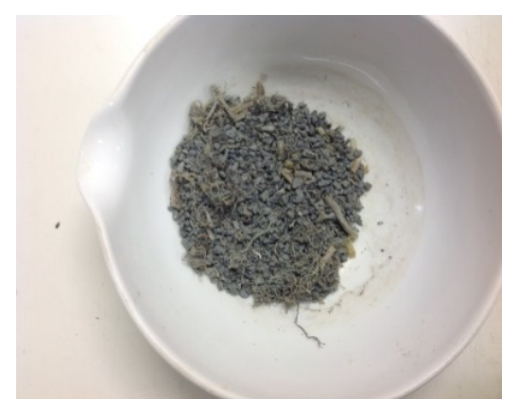

Figure 5. Close appearance of removed lead sinker.

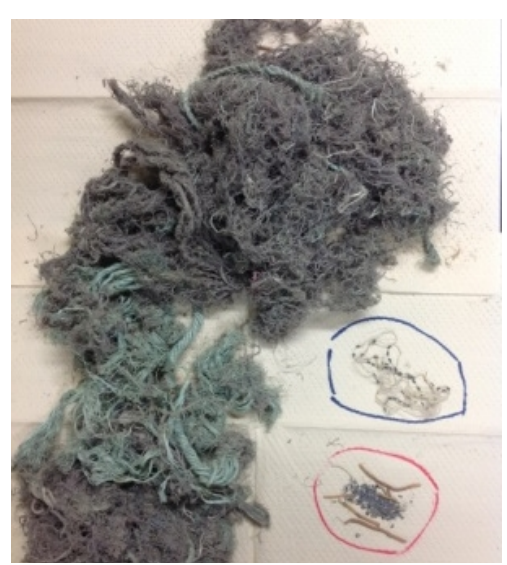

Figure 6. State of ropes after treatment. 
form of ropes (Photo not shown). Based on these findings, it was concluded that the used ropes experienced material degradation resulting from long periods of use in seawater.

\subsection{Proposed System for Treatment of Fishing Net with Lead-Core Ropes}

As stated, following mechanical shredding, the used ropes showed a cotton-like structure that easily trapped the lead sinkers (see the red circle in Figure 5). Despite being successfully removed from the used rope, a considerable proportion of the lead sinkers therefore became trapped within the shredded rope structure and was not collected, thereby greatly reducing the recovery efficiency from the used ropes. Consequently, the removal and subsequent collection of lead sinkers from used ropes require different processes. Fishing net made from lead sinker-cored ropes must be pre-cut before passing through the shredding machine. Figure 7 describes a system for total treatment of fishing nets made from lead-core sinker ropes: used fishing nets are cut to lengths of approximately $1 \mathrm{~m}$ and sent to a lead removal process. After removal of lead sinkers, the fishing nets proceed to a collection process in order to entirely separate the removed lead sinkers and the treated ropes. In Figure 6, lead sinkers in the blue circle were not removed from the ropes following 30-second treatment time, indicating that much longer shredding time was required. At 60 seconds, there were no lead sinkers visible in the ropes, suggesting this duration of treatment is necessary for complete removal of lead sinkers.

\section{Conclusion}

Publicized management reports show that fishing nets with lead-weighted rope core are currently landfilled or incinerated in Japan without lead removal. This makes the treatment of fishing nets more complicated and troublesome. Incineration ash and leachate with high lead concentration become the secondary environmental concerns. We propose a promising method for the treatment of fishing nets and recovery of lead weights. The present study identified some critical points for improved treatment of fishing nets. Lead sinkers cored in ropes of fishing nets were successfully removed by a revolving cross-flow waste-shredding machine. A treatment time of 60 seconds was appropriate. It was found that lead sinkers comprised 35\% - 60\% of the total weight of fishing nets, and that recovered lead sinkers were of high quality suitable for resale as base metals. In terms of constructing a total treatment system for the fishing nets containing lead sinkers, it can be concluded that three steps are necessary, i.e. pre-treatment, main treatment, and post-treatment since the removal of lead sinkers and subsequent collection stage required different processes, especially when treating used fishing nets. It is very important to address secondary environmental concerns associated with the mismanagement of lead sinkers contained in fishing nets, and material recovery also has very important implications for the conservation of valuable natural resources. It is hoped that the findings of this study will accelerate the recovery of lead from fishing nets and prevent secondary environmental pollution.

\section{Acknowledgements}

The authors are grateful to local government officers of Miyagi Prefecture and the personnel of the Kesennuma

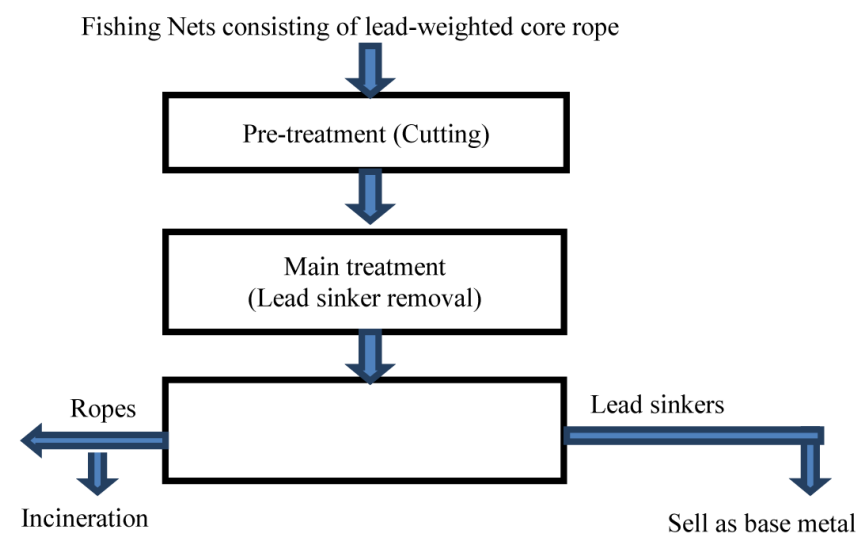

Figure 7. Example of a figure caption (figure caption). Total treatment system for fishing nets made from lead sinker cored ropes. 
Earthquake Disaster Debris Treatment Site (Kesennuma Block) in Miyagi Prefecture, Japan, for their cooperation and assistance in conducting the field treatment of used fishing nets obtained from disaster debris.

\section{References}

[1] Science Direct (2013) http://www.sciencedirect.com/

[2] Meyer, P.A., Brown, M.J. and Falk, H. (2008) Global Approach to Reducing Lead Exposure and Poisoning. Mutation Research, 659, 166-175. http://dx.doi.org/10.1016/j.mrrev.2008.03.003

[3] Pokras, M.A. and Chafel, B.A. (1992) Lead Toxicosis from Ingested Fishing Sinkers in Adult Common Loons (Gaviaimmer) in New England. Journal of Zoo and Wildlife Medicine, 23, 92-97.

[4] Yoichi, Y., Shigeki, Y., Hiroshi, I., Hiroyuki, O. and Yoshiaki, O. (1996) Acute Lead Poisoning froms Fishing Sinker. Journal of Journal of Japanese Association for Acute Medicine, 7, 669-672.

[5] Scheuhammer, A.M. and Norris, S.L. (1996) The Ecotoxicology of Lead Shot and Lead Fishing Weights. Ecotoxicology, 5, 279-295. http://dx.doi.org/10.1007/BF00119051

[6] Borkowski, R. (1997) Lead Poisoning and Intestinal Perforations in a Snapping Turtle (Chelydraserpentina) due to Fishing Gear Ingestion. Journal of Zoo and Wildlife Medicine, 28, 109-113.

[7] Thomas, V.G. (1997) Attitudes and Issues Preventing Bans on Toxic Lead Shot and Sinkers in North America and Europe, Environmental Values, 6, 185-199. http://dx.doi.org/10.3197/096327197776679176

[8] Twiss, M.P. and Thomas, V. (1998) Preventing Fishing-Sinker-Induced Lead Poisoning of Common Loons through Canadian Policy and Regulative Reform. Journal of Environmental Management, 53, 49-59.

http://dx.doi.org/10.1006/jema.1998.0190

[9] Mowad, E., Haddad, I. and Gemmel, D.J. (1998) Management of Lead Poisoning from Ingested Fishing Sinkers. Archives of Pediatrics and Adolescent Medicine, 152, 485-488. http://dx.doi.org/10.1001/archpedi.152.5.485

[10] Duerr, A.E. and DeStefano, S. (1999) Using a Metal Detector to Determine Lead Sinker Abundance in Waterbird Habitat. Wildlife Society Bulletin, 27, 952-958.

[11] Jacks, G., Byström, M. and Johansson, L. (2001) Lead Emissions from Lost Fishing Sinkers. Boreal Environment Research, 6, 231-236.

[12] Scheuhammer, A.M., Money, S.L., Kirk, D.A. and Donaldson G. (2003) Lead Fishing Sinkers and Jigs in Canada: Review of Their Use Patterns and Toxic Impacts on Wildlife, Canadian Wildlife Service, 108, Canada.

[13] Thomas, V.G. and Raimon G. (2003) Lead Pollution from Shooting and Angling, and a Common Regulative Approach. Environmental Policy and Law, 33, 143-149.

[14] Thomas, V.G. (2003) Harmonizing Approval of Nontoxic Shot and Sinkers in North America. Wildlife Society Bulletin, 31, 292-295.

[15] Takahashi, M., Seimiya, Y.M., Asano, T., Tamura, T., Kubo, M., Kimura, K.M. and Haritani, M. (2003) Lead Poisoning with Neuropil Vacuolation at the Bovine Dorsal Vagus Nuclei. Journal of the Japan Veterinary Medical Association, 56, 249-252.

[16] Franson, J.C., Hansen, S.P., Creekmore, T.E., Brand, C.J., Evers, D.C., Duerr, A.E. and DeStefano, S. (2003) Lead Fishing Weights and Other Fishing Tackle in Selected Waterbirds. Waterbirds, 26, 345-352. http://dx.doi.org/10.1675/1524-4695(2003)026[0345:LFWAOF]2.0.CO;2

[17] Thomas, V.G. and Raimon, G. (2005) Role of International Conventions in Promoting Avian Conservation through Reduced Lead Toxicosis: Progression toward a Non-Toxic Agenda. Bird Conservation International, 15, 147-160. http://dx.doi.org/10.1017/S0959270905000110

[18] Zabka, T.S., Martin, H., Birgit, P., Frances, M.D.G., Patricia, A.C. and Lowenstine, L.J. (2006) Acute Lead Toxicosis in a Harbor Seal (Phocavitulinarichardsi) Consequent to Ingestion of a Lead Fishing Sinker. Journal of Wildlife Diseases, 42, 651-657. http://dx.doi.org/10.7589/0090-3558-42.3.651

[19] Scott St. Clair, W. and Benjamin, J. (2008) Lead Intoxication from Ingestion of Fishing Sinkers: A Case Study and Review of the Literature. Clinical Pediatrics, 47, 66-70. http://dx.doi.org/10.1177/0009922807304135

[20] Vernon, G.T. and Raimon, G. (2010) Limitations of European Union Policy and Law for Regulating Use of Lead Shot and Sinkers: Comparisons with North American Regulation. Environmental Policy and Governance, 20, 57-72. http://dx.doi.org/10.1002/eet.527

[21] Carrier, P., Legros, R., Le Sidaner, A., Morel, A., Harry, P., Moesch, C., Sautereau, D., Ly, K.H. and Loustraud-Ratti, V. (2012) Lead Poisoning by Fishing Sinker Ingestion. Le Revue de médicine interne, 33, 697-699.

[22] Mathee, A., Khan, T., Naicker, N., Kootbodien, T., Naidoo, S. and Becker, P. (2013) Lead Exposure in Young School Children in South African Subsistence Fishing Communities. Environmental Research, 126, 179-183. 
http://dx.doi.org/10.1016/j.envres.2013.05.009

[23] Japan Mining Industry Association (2013) Lead Consumption and Use in Japan. http://www.jlzda.gr.jp/namari/co/na_co01.htm

[24] Yoshino, H., Fujiwara, T. and Yamamoto, K. (2010) Development of Lead Free Fishing Sinker. Nippon Suisan Gakkaishi, 76, 799-802. http://dx.doi.org/10.2331/suisan.76.799

[25] Personal Communication.

[26] Kanazawa City (2012) Outline of Kanazawa City Disaster Debris Acceptance (Fishing Gear and Nets).

[27] Tateda, M. and Yamada, H. (2011) Feasibility Study of Proper Treatment and Recycle Waste Location Fixed Fishing Nets. The 22nd Annual Conference Japan Society of Material Cycles and Waste Management, Toyo, Toyo University, 1-3 November 2011.

[28] Tateda, M. (2012) Proper Treatment and Recycle Waste Location Fixed Fishing Nets. Plastics, 13-16.

[29] Tateda, M., Yamada, H., Horigome, Y., Sato, F., Yamamoto, T. and Hagiwara, J. (2013) Lead Removal from Waste Fishing Nets at Kesennuma Block. The 24th Annual Conference of Japan Society of Material Cycles and Waste Management, Sapporo, 2-4 November 2013.

[30] Tateda, M., Yamada, H., Horigome, Y., Sato, F., Yamamoto, T. and Hagiwara, J. (2013) Field Study of Lead Removal from Disaster Debris Fishing Net. The 50th Annual Conference of Japanese Society of Water Treatment Biology, 2013, 54.

[31] Tateda, M., Yamada, H., Horigome, Y., Sato, F., Yamamoto, T. and Hagiwara, J. (2014) Field Study of Lead Removal from Disaster Debris Fishing Net at Kesennuma Treatment Block. The 35th Annual Conference of Japan Waste Management Association, January 2014. 